\title{
Baş boyun kanser hastalarında yeni geniş çaplı bir trokarın introducer tekniği ile perkutan endoskopik gastrostomi için uygulanımı
}

\author{
A new large-caliber trocar for percutaneous endoscopic gastrostomy by the introducer technique in \\ head and neck cancer patients
}

Giordano-Nappi JH, Maluf-Filho F, Ishioka S, Hondo FY, Matuguma SE, Simas de Lima M, Lera Dos Santos M, Retes FA, Sakai P. Endoscopy 2011;43:752-8.

Baș boyun kanserli (BBK) hastalarda, çekme yöntemi ile yapılan perkütan endoskopik gastrostomi (PEG) tekniği olguların en az \%30'unda başarısız olmaktadır. Çekme tekniği ile yapılan PEG işleminde stoma enfeksiyonu ve daha düşük olmakla beraber kanser hücresinin yayllım riski bulunmaktadır. Bu çalışmada yeni geniş çaplı bir trokar içinden 20F çapında besleme tüpünün intruducer PEG tekniği ile uygulanılabilirliği araştırılmış. Bu amaçla farengo-özofageal stenozu olan 23 ve trismusu olan 9 BBK olgusunda Karnofsky indeksi 50'nin altında olması, solunum yetmezliği, asit, daha önce geçirilmiş gastrektomi, karın ön duvarı transilluminasyonunun olmaması, solunum yetmezliği, peritonit, karın ön duvarı enfeksiyonu, intestinal tıkanıklık varlığı çalışmaya alınmama kriterleri olarak kabul edilmiş. Tüm hastalara cefazolin $2 \mathrm{~g}$ iv, işlemden 30 dakika önce enjekte edilmiş. Bu yeni trokar 10 mm çapında çelikten yapılmış olup, yan fissür ve distalinde konikal uç olan obturatör (örtücü) mevcut imiş. Yan fissürden $20 \mathrm{~F}$ gastrostomi kateteri rahatça geçebilmekte ve konikal ucun karın ön duvarına daha az travmatik olduğu bildirilmektedir. Gastropeksi sütürleri arasına gelecek şekilde 10

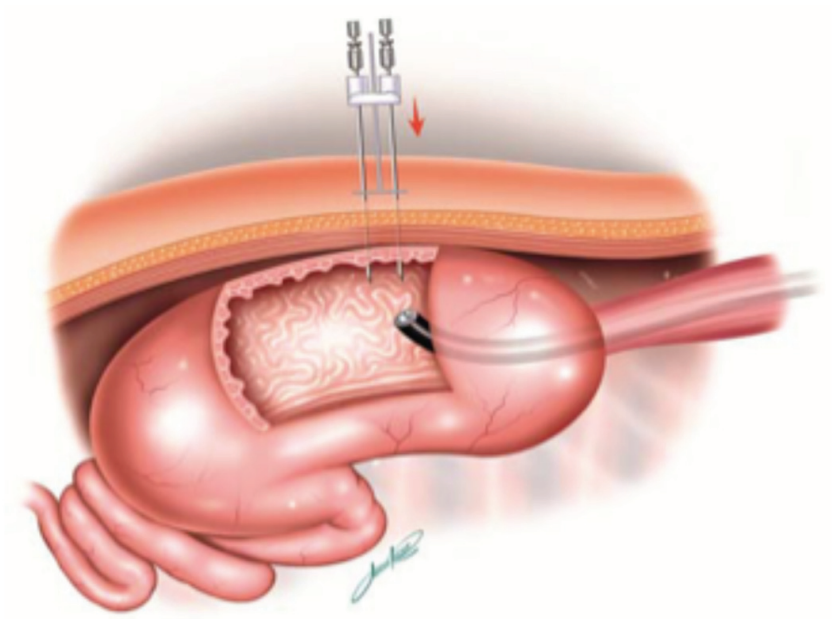

Figure 1. Gastropeksi-endoskopi kontrolünde. mm'lik karın cildi kesisi yapıldıktan sonra, trokar endoskopik gözlem ile karın/mide duvar katmanlarını fikse edecek şekilde basınç ile mide içine sokulmuş. Obturatör çıkartıldıktan sonra 20F kateter yan yarıktan içeri yerleştirilebilmiş. Ardından mide içinde balon şişirilmiş ve besleme tüpü mide içinde sabitlenebilmiş. Isşlem her hastada başarılı olmuş, hiçbir olguda komplikasyon gelişmemiş ve yine hiçbir olguda tümör dilatasyonu yapılmadan 5.9 mm'lik pediatrik gastroskopla işlemler 12-25 dakika içinde gerçekleştirilmiş. Gastrostomi

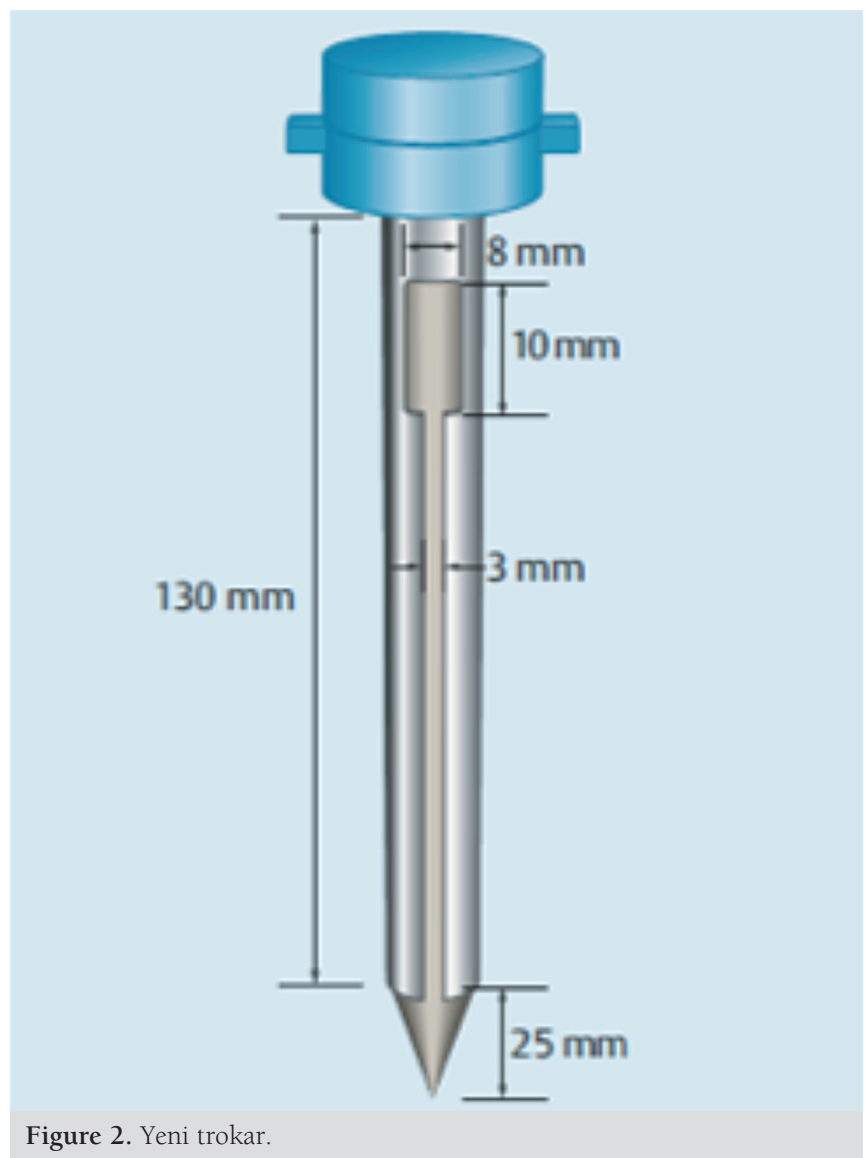

Iletișim: Yücel ÜSTÜNDAG Zonguldak Karaelmas Üniversitesi Tıp Fakültesi, ıç Hastalıkları Anabilim Dalı, Gastroenteroloji Bilim Dalı, Zonguldak, Türkiye Tel: + 9037226101 55 • E-mail: yucel_u@yahoo.com Gelis Tarihi: 10.12.2011 Kabul Tarihi: 10.12.2011 


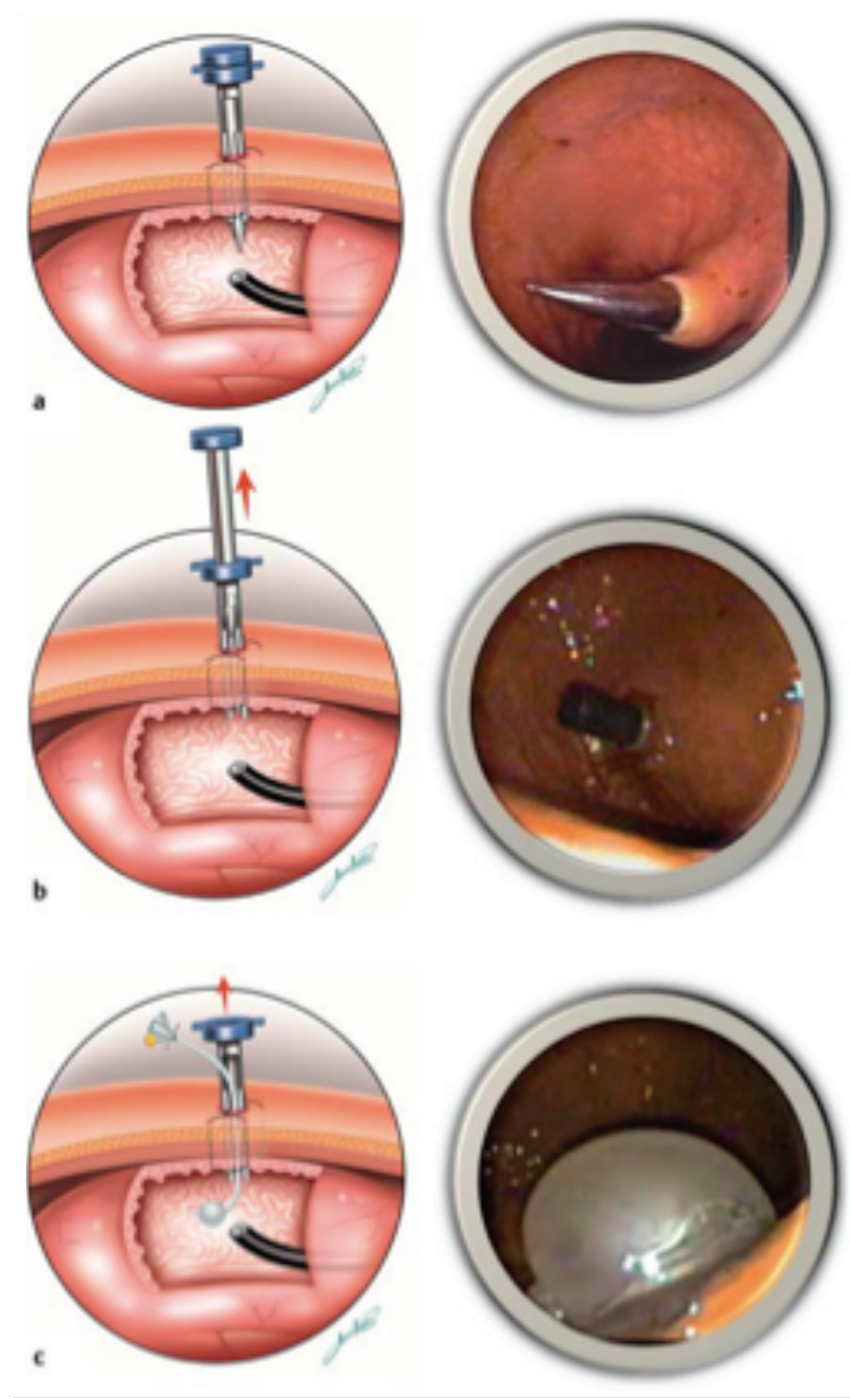

Figure 3. Gastropeksi sonrası trokar içinde balonlu besleme tüpü yerleştirilmesi.

hattında ağrı olguların çoğunda hafif iken birinde ciddiymiş. Taşikardi ve karında hassasiyet gelişen olguda eksploratif laparotomi uygulanmıs. Ancak, perforasyon, batına mide içeriğinin geçişi veya ek cerrahi gerektirecek bir bulguya rastlanmamış ve olgu kısa süre içinde kendiliğinden toparlamış. Bu olguda ağrının nedeni olarak ciddi pneumoperitoneum olduğu düşünülmüş. Balon yırtılan 2 olguda ise gatrostomi hattından beslenme tüpü yerleştirilmiş. Işleme bağlı mortalite hiçbir olguda görülmemiş.

\section{YORUM}

Biliyoruz ki, çekme tekniği ile yapılan PEG uygulamasının başarısı BBK olgularda \%80'lere kadar inebilmektedir. Bunun nedeni, neoplastik farengoözofageal stenoz, trismus olarak sayılabilir. Bu olgularda pediatrik endoskoplar kullanılsa dahi, gastrostomi tüpüne ait 25 mm'lik iç bumperın mideye yerleştirilebilmesi mümkün olmayabilmektedir. Farengo-özofageal darlığın buji ve balon ile genişletilebilmesi perforasyon ve kanama riski taşımaktadır. Bu uygulamanın çeşitli daha invaziv alternatifleri, cerrahi gastrostomi, rijid larengoskop kullanımı veya farenks cerrahisi sırasında tümör rezeksiyonu sonrası PEG yerleştirilmesi olarak sayllabilir. Diğer bir yöntem ise introducer tekniği ile yapılan PEG uygulamasıdır. Bu uygulamayı çekme tekniği ile karşılaştıran birkaç adet araştırmada, daha düşük peristomal infeksiyon ve aspirasyon pnomoni riski ve daha kısa süreli hastanede kalış süresi sağladığı raporlanmıştır (Tucker AT, et al. Laryngoscope 2003, Deitel M, et al. Can J Surg 1988, Toyama Y, et al. Surg Endosc 2007). Ilk uygulamalarda introducer tekniği ile başarı düşük iken, bu yönteme gastropeksi eklenmesi ile başarı oranları yükseltilmiştir. Gastropeksi ile bu çalışmada olduğu gibi güvenli olarak mideye girilebilmektedir. Bu çalışmada yazarların vurguladığı en önemli nokta, SLIC ve ekstrakorporeal PEG yöntemlerinden farklı olarak tek aşamalı olarak trokar ile mideye girilebilmesidir. Diğer önemli bir nokta ise bu kadar büyük bir trokar ile karın ön duvarı ve mideden geçilmesine rağmen çok ciddi ağrının sadece bir hastada olmasıdır. Hafif ağrı tüm hastalarda olmakla beraber bu olguların \%73'ünde 20 gün içinde tam olarak ağrı palyasyonu olduğu dikkatimizi çekmiştir. Yani, potansiyel ağrı sorunu bu yöntemin uygulanmaması için bir neden değildir.

Bu çalışmada tüm hastalara profilaktik antibiyotik uygulanması yapıldığı görülmektedir. Halbuki, bir çok çalışmada belirtildiği gibi introducer tekniği ile yapılan PEG uygulamalarında profilaktik antibiyotik kullanım endikasyonu yoktur. Yazarlar bu konuda açıklamalarını, yeni bir cihaz uygulayacaklanı için antibiyotik kullanım gerektiğini ifade etmişlerdir. Diğer bir nokta ise çekme tekniği ile yapılan PEG uygulamasinda düşükte olsa (<\%1) tümör yayılımı riski bulunmaktadır. Bu çalışmada ise işlem sonrası olguların kısa süreli takibi nedeni ile gastrostomi hattında ortaya çıkabilecek metastaz açısından bir bilgi mevcut değildir.

Sonuç olarak bu yeni trokarla, mide ve karın ön duvarı gastropeksi ile birleştirildikten sonra, tek bir uygulama ile 20F balonlu besleme kateteri başarn ile majör bir komplikasyon olmadan uygulanabildiği anlaşılmaktadır. Bu yeni trokarın sayesinde BBK'li faringo-özofageal darlığı veya trismusu olan olgularda PEG yerleştirilmesinde belirgin kolaylık ve hız sağlayacağı görülmektedir.

\section{Yücel ÜSTÜNDAĞ}

